\title{
Ectopic Expression of DSCR1 in Conjunction with NDV Infection Reduces VEGF and Induces Apoptosis in Lung Cancer A549 Cell Line
}

Hanie Motahary Rad, Zahra Niki Boroujeni and Ahmad Aleyasin*

Department of Medical Biotechnology, National Institute of Genetic Engineering and Biotechnology, Tehran, Iran

\begin{abstract}
Lung cancer is one the most cause of cancer related deaths in the world. Newcastle Disease Virus (NDV) is an oncolytic and targeted self-amplifying agent that is able to replicates and kills only cancer cells. The strongest limitation of NDV in cancer treatments is due to its angiogenesis effect for tumors formation. The NDV mechanism for angiogenesis has not been described. This study was to evaluate for the first time the anti-angiogenesis effect of DSCR1 lonely and in conjunction with NDV in lung cancer cells. Ectopic expression of DSCR1 was induced by lentiviral transfection to A549 cell line. Transfected A549 was treated with the effective dose of NDV. Total RNA was extracted and cDNA was synthesized to detect DSCR1, VEGF, PCNA, Bax, and Bcl2 genes expressions compare to HPRT expression as a housekeeping gene using SYBR green Real-time PCR assay. Over expression of VEGF was detected in RNA level for the first time in NDV treated cells. Significant fold changes of PCNA, Bax, and $B c / 2$ showed that NDV used mitochondrial pathway for induction of cell death. In LVDSCR $1^{+}$treated cancer cells, DSCR1 ectopic expression acts as an anti-angiogenesis factor, by reducing VEGF and inhibiting angiogenesis signaling pathway. Furthermore, the apoptotic effect for DSCR1 gene was shown for the first time in this study in lung cancer cells. A non-significant change in Bax and Bc/2 gene expression has suggested a lack of intracellular apoptosis pathway activity following DSCR1 over expression in cancer cells. In LVDSCR+ + NDV treated cancer cells, over expression of DSCR1 could modulate angiogenesis effect of NDV by VEGF reduction and accelerate apoptosis induction in cancer cells as well. This finding for the first time suggests the benefit and potential usefulness in simultaneous application of oncolytic viruses and gene therapy in cancer treatment.
\end{abstract}

Keywords: Newcastle disease virus; Lung cancer; Apoptosis; Antiangiogenesis

\section{Introduction}

Cancer is a devastating life-threatening disease arises from both genetic and environmental factors and caused by defects in the signaling mechanisms that control cell proliferation and apoptosis. Molecular mechanism defects that regulate cellular growth and death, allowing tumor cells to have uncontrolled division and the ability to metastasis $[1,2]$.

Lung cancer is the second newly diagnosed cancer that accounts for the most related cancer-deaths in both genders in the world $[3,4]$. The primary lung cancer can grow locally or cause metastasis in other tissues [4]. The most frequent lung cancers is Non-Small Cell Lung Cancer (NSCLC) that consist of $80 \%$ of all kinds of lung cancer [5-7]. Despite of conventional therapies and novel progressed techniques in diagnosis and therapy, breast cancer still a devastating disease worldwide, therefore it has provided an incentive for searching of new more effective and with less side effect therapeutics. The purpose of cancer therapy is to destroy malignant cells without causing destruction of normal cells. One of the novel therapeutic that gives much hopes is using of oncolytic viruses that can selectively replicate in cancer cells [8].

Newcastle Disease Virus (NDV) as a member of oncolytic viruses (OVs) is also known as a member of genus Avulavirus within the family Paramyxoviridae $[9,10]$. The NDV is a negative-sense single stranded RNA virus that has a genome with a length of $15 \mathrm{~kb}$, including six genes encoding at least eight proteins by alternative splicing: structural proteins (NP, P, M, F, HN, L) and non-structural proteins (V and W) [11-14]. NDV is targeted self-amplifying agent that is able to replicates and kills only cancer cells $[11,12,15,16]$ by fuses into and replicates within the infected cells' cytoplasm independent of cell proliferation [17]. NDV exert anti-tumor cytotoxic effect based on host's anti-tumor immunity stimulation and oncolytic activity [18]. NDV can replicates in cells with deficient interferon pathway $[17,18]$. Their selectivity for neoplastic cells are 10000 fold higher than normal cells and are relatively safe for normal cells. The significant feature of NDV is its ability to selectively replicate in cancer cells. Virus replication is limited to the cell cytoplasm without integration or recombination. Apoptosis naturally occurs in tissues in order to maintain the survival of the cell population. According to the previous researches, NDV induced cell death stems from apoptotic reaction and probably it leads to oncolysis natural feature of NDV. Possessing various unique properties considers NDV a great agent for cancer therapy; for instance: good cell binding properties, selectively replication in tumor cell cytoplasm, rather safe and also the property of acting as an adjuvant. It has been suggested that differences in innate immune responses between normal and tumor cells cause to the selectivity of NDV and other oncolytic viruses to cancer cells. The replication of NDV in cancer cells enhances due to the type I interferon (IFN) response defection of these cells and hence destruction has been increased. IFN production inhibits viral replication when normal cells have been infected. NDV infects the host cells and then replicates itself similar to other viruses but interesting point is that NDV can replicate itself more quickly (up to 10000 times) in human neoplastic cells than in normal cells and cause oncolytic effects. According to the primary researches NDV induced apoptosis through IFN- $\alpha$, TNF- $\alpha$ and TRAIL

*Corresponding author: Ahmad Aleyasin, Department of Medical Biotechnology, National Institute of Genetic Engineering and Biotechnology, Tehran-14155-6343, Iran, Tel: +98-21-44580383; Fax: +98-21-44580395; E-mail: seyedahmadaleyasin@gmail.com

Received October 06, 2018; Accepted January 16, 2019; Published January 18, 2019

Citation: Rad HM, Boroujeni ZN, Aleyasin A (2019) Ectopic Expression of DSCR1 in Conjunction with NDV Infection Reduces VEGF and Induces Apoptosis in Lung Cancer A549 Cell Line. J Cancer Sci Ther 11: 001-008. doi: 10.4172/19485956.1000574

Copyright: (c) 2019 Rad HM, et al. This is an open-access article distributed under the terms of the Creative Commons Attribution License, which permits unrestricted use, distribution, and reproduction in any medium, provided the original author and source are credited. 
signal molecules. TNF- $\alpha$ and TRAIL are apoptosis inducers and meanwhile they display an antitumor activity [19-22].

The biggest limitation of using NDV for cancer treatments is the increasing level of angiogenesis in tumors. Cells that have been treated with oncolytic viruses, due to the destruction of tissue homeostasis conditions, disturb the balance between angiogenesis and antiangiogenesis factors. These balance changes switch on the angiogenesis pathway and provides the conditions for the formation of new blood vessels $[23,24]$. In order to solve this problem has had many strategies were examined [23]. To date, some anti-angiogenesis genes were transfected to cancer cells by engineered oncolytic viruses [25-28].

Gene therapy is the leading way to treat cancer in many investigational models. This method is based upon the recognition of tumor suppressor or suicide proteins encoding genes and transferring them into tumor cells by means of a genetic vector. Viruses are mostly chosen as vehicles for gene therapy because they have evolved very effective mechanisms of gene transfer and expression. Angiogenesis has vital role to tumor progression therefore it can be a significant target for anticancer treatment. Vascular endothelial growth factor-A (VEGFA; also referred to as VEGF) is one of the critical factors for solid tumor growth through stimulating of angiogenesis. It is suggested that the reduction occurrence in many cancer types in Down syndrome patients can be due to the high expression of some genes on chromosome-21 such as Down syndrome critical region-1(DSCR1) encoding a protein which can suppress (VEGF)-mediated angiogenic signaling via the calcineurin pathway. DSCR1 is a gene situated in the $21 \mathrm{q} 22.1-\mathrm{q} 22.2$ region of human chromosome 21 [29,30]. The DSCR1 gene consists of seven exons [31,32]. Commonly, exons 1-4 can be alternatively spliced to produce four different mRNA isoforms [33] which have different N-terminal but identical at the C-terminal domains [29]. DSCR1 (RCAN1) is a calcineurin binding protein [31,34] which is characterized as an inhibitor of the calcineurin phosphatase [35] by a negative feedback loop formation in cells regulating calcineurindependent dephosphorylation [36]. DSCR1 overexpression blocks NFAT transcriptional activity and down regulates COX2 and VEGF genes [37]. DSCR1-4 is capable of inhibiting the formation of new blood vessels [38] thus it was used as an anti-angiogenic agent in this study and gene transfer to cells was performed via lentiviral vectors.

Lentiviruses are a large member of Complex Retroviridae diploid single-stranded positive sense RNA viruses [39,40]. Due to their ability to infect a wide variety of dividing and non-dividing cells, they have gained much attention as gene delivery tools over the past decade [39-41]. LVs can encompass large transgenes as large as about 10 kilobases $(\mathrm{kb})$ [42]. These vectors, such as those based on human immunodeficiency virus 1 (HIV-1), transduce a variety of cell types, including embryonic and adult stem cells, and have been suggested as candidate vectors for both in vivo and ex vivo gene therapy applications. However, integration of viral genome into host cell genome may induce some adverse effects, such as insertional mutagenesis; this has been highlighted by the induction of malignancy in mouse models and development of leukemia in five patients in two clinical gene therapy trials. Improving safety and efficiency of LV has been achieved, for example, by modifications of packaging cassettes on the virus integrase gene or on other regions of virus genome. This virus, which is called the nonintegrated LV, cannot integrate into the host genome.

In this study, for the first time simultaneous using of NDV and DSCR 1 gene as a reducing agent of angiogenesis were examined. Both integrating and non-integrating LVs were used as viral vectors for gene transfer to investigate effects of NDV and ectopic DSCR1 gene overexpression on apoptosis and expression of angiogenesis markers in A549 cells.

\section{Materials and Methods \\ Chick embryo fibroblast cell culture}

A 9-11 days-old embryonated chicken eggs were used to prepare Chicken Embryonic Fibroblast (CEF) monolayer [43]. Briefly the air sac of eggs was marked and embryos were aseptically removed from the eggs, washed in phosphate buffered saline (PBS) and head, legs, wings and viscera were cut and discarded. The rest of the body portions were washed by PBS and digested by collagenase solution (Sigma) at a final concentration of $0.075 \%$ for 30 minutes. Digested tissues were centrifuged at $400 \mathrm{~g}$ for $10 \mathrm{~min}$. Pellets were resuspended and cultured at a density of $2 \times 10^{6}$ cells $/ \mathrm{mL}$ in $25 \mathrm{~cm}^{2}$ plastic culture flask in high glucose Dulbecco's modified Eagle's medium (DMEM) (Sigma, USA) containing $50 \%$ fetal bovine serum (FBS), $100 \mathrm{U} / \mathrm{mL}$ penicillin/ streptomycin and incubated at $37^{\circ} \mathrm{C}$ in $\mathrm{CO}_{2}$ incubator with $5 \% \mathrm{CO}$ for $24 \mathrm{~h}$. Non adherent cells were washed away with PBS and CEFCs were cultured in DMEM containing 20\% FBS and antibiotics. Upon $80 \%$ confluency, the cells were harvested using $0.25 \%$ Trypsin- $0.02 \%$ EDTA for $1-2 \mathrm{~min}$ at $37^{\circ} \mathrm{C}$ and were kept frozen in liquid nitrogen for later use.

\section{Newcastle Disease Virus (NDV)}

A commercial vaccine (LaSota strain) was obtained from poultry vaccine production department, Razi vaccine and serum research institute, Tehran, Iran and kept at $4^{\circ} \mathrm{C}$ till used. A vial of lyophilized vaccine (2000 dose/vial) was reconstituted with $2 \mathrm{ml}$ sterile phosphate buffered saline (PBS), and stored at $-70^{\circ} \mathrm{C}$ in $0.2 \mathrm{ml}$ aliquots.

\section{Adaptation and propagation of NDV to in vitro conditions}

For virus adaptation, medium of the confluent CEFCs monolayer plate was discarded and cells were gently washed with PBS. $100 \mu \mathrm{l}$ of virus from stocks stored at $-70^{\circ} \mathrm{C}$ was added to the CEFCs monolayer plate. PBS was added to other confluent CEFCs monolayer as negative control. The plate was incubated at $37^{\circ} \mathrm{C}$ in an atmosphere of $5 \% \mathrm{CO}$ and $80 \%$ relative humidity for $1 \mathrm{hr}$. $4 \mathrm{ml}$ DMEM growth medium supplemented with $3 \% \mathrm{FBS}, 100 \mathrm{U} / \mathrm{mL}$ penicillin/streptomycin was added to the confluent monolayer cells and kept in $\mathrm{CO}_{2}$ incubator at $37^{\circ} \mathrm{C}$ with $5 \% \mathrm{CO}_{2}$ for 3 days. After 3 days plate was incubated in $-20^{\circ} \mathrm{C}$ until freeze-thaw cycles rapidly for cell explosion and virus releasing into medium. The medium was filtered with $0.22 \mu \mathrm{m}$ filter. The process repeated with $100 \mu \mathrm{l}$ of this adapted virus and Subsequent passage was done as well for virus propagation. Medium containing virus stored at $-70^{\circ} \mathrm{C}$. Infected monolayers were checked twice a day under an inverted microscope to observe any changes compare to non-infected cells.

\section{Cancer and normal cell lines}

The human NSCLC A549 lung cancer cell line and human fibroblasts HU02 were purchased from National Center of Genetic and Biological Reserves (Tehran, Iran). Cell line A549 was cultured using Dulbecco's Modified Eagle's Medium/Nutrient F-12 Ham (DMEM/F-12, GIBCO) and cell line HU02 was cultured in DMEM (GIBCO) both supplemented with $10 \%$ fetal bovine serum (FBS, GIBCO).

\section{Construction of integrated and non-integrated lentiviruses DSCR1 ${ }^{+}$particles}

The LV DSCR $1^{+}$virus particles were constructed in transfected HEK 
Citation: Rad HM, Boroujeni ZN, Aleyasin A (2018) Ectopic Expression of DSCR1 in Conjunction with NDV Infection Reduces VEGF and Induces Apoptosis in Lung Cancer A549 Cell Line. J Cancer Sci Ther 11: 399-405. doi: 10.4172/1948-5956.1000574

293T cells. HEK 293T cells were transfected with plox-MD2 (pmd2G) plasmid which contained $G$ protein of the vesicular stomatitis virus (InvivoGen), pLV-HELP expression vector encoding the non-integrate packaging proteins Gag- Pol- Rev- Tat (InvivoGen), psPAX, integrated packaging plasmid (InvivoGen) and finally transfer vector EX-S0552LV-105-B harboring DSCR1 gene(GeneCopia). The culture medium was discarded 14 hour after transfection and fresh culture medium was added to the culture flask. 24 hours after changing the medium, lenti virus particles were released into culture medium. Lenti viruses were collected and concentrated by MILLIPORE falcons to be kept in $-70^{\circ} \mathrm{C}$.

\section{Ectopic expression of DSCR1 gene in HEK293T}

HEK 293T cells were infected with LV DSCR1+. Total RNA was extracted 24 hour after infection (RNX plus, Fermentas, EU) and cDNA synthesis was performed using cDNA synthesis kit and Oligo(dT) primers (Fermentas, EU). Real time-PCR was performed in a 15 $\mu \mathrm{l}$ reaction volume by designed primers for DSCR1 gene (Table 1).

\section{MTT Assay to determine effective concentrations of NDV and LV-DSCR1 ${ }^{+}$}

MTT assay was performed to determine the effective concentrations for NDV and LV-DSCR1 ${ }^{+}$concentrations in A549 and HU02. These cell lines were seeded in three separate 96 -well microtiter plates $(7000$ cell/well) in three repeat wells and incubated for 24 hours. NDV was added to A549 (0- 0.01- 0.1- 1- $10 \mu \mathrm{l}$ ) and HU02 (0- 0.1- 0.5- 1- 2- 4- 816- $32 \mu \mathrm{l})$. They were infected with different volumes of Lenti viruses (LV Int. DSCR ${ }^{+}$(0- 1- 2- 3- 4- 5- 6-7 $\mu$ l for A549 and 0- 1- 3- 6- 12- 24$48 \mu \mathrm{l}$ for HU02 cell lines) and LV Non Int. $\mathrm{DSCR}^{+}(0-0.1-0.2-0.4-0.8-$ 1.6- $3.2 \mu \mathrm{l}$ for A549 and 0- 0.8- 1.6- 3.2- 6.4- 12.8- $25.6 \mu \mathrm{l}$ for HU02 cell lines) in two separate 96 -well microtiter plates. MTT assay was done on Sigma Protocol. The plates were shaken gently and optical density (OD) was measured at $580 \mathrm{~nm}$ to determine the relative cell viability.

\section{Apoptotic and angiogenesis effects of NDV and LV-DSCR1 ${ }^{+}$ in A549 cell line}

A549 cell was cultured in two 24 wells plates $3.5 \times 10^{4}$ A549 cells/ well for 24 hours to become $70 \%$ confluence in three repeat wells and one well non-treated control for each treatment in five different treatment conditions. First one treated with NDV $(0.5 \mu \mathrm{l})$ alone, and second and third treatments with integrated $(30 \mu \mathrm{l})$ and non-integrated LV-DSCR1 $1^{+}(4 \mu \mathrm{l})$ and forth and five conditions with simultaneous treatment NDV+ integrated LV-DSCR1 $1^{+}(0.5 \mu \mathrm{l} \mathrm{NDV/} 30 \mu \mathrm{LV}$ $\left.D S C R 1^{+}\right)$and NDV + Non-integrated LV-DSCR1 $1^{+}(0.5 \mu \mathrm{l} \mathrm{NDV/} 4$ $\mu \mathrm{LV}-D S C R 1+)$. First pale was harvested after 24 hours and second plate was harvested after 72 hours of treatment. Cells from all wells were harvested after treatment, total RNA was extracted (RNX plus, Fermentas, EU) and cDNA synthesis was performed using cDNA synthesis kit and Oligo-(dT) primers (Fermentas, EU).

\section{Real Time PCR}

To determine expressions of genes involve in apoptosis and angiogenesis after five different treatments with NDV and LV$D S C R 1^{+}$, all samples were tested for DSCR1, VEGF, PCNA, Bax, $B c l 2$, expressions of compare to HPRT expression as a housekeeping gene with SYBR green Real-time PCR assay. The SYBR green reaction was obtained from BIONEER, Korea, 2X Greenstar qPCR Master Mix kit. The Real-time PCR was performed in 42 cycles each cycle $95^{\circ} \mathrm{C}$ for 30 sec, and $62^{\circ} \mathrm{C}$ for $60 \mathrm{sec}$ with initial $95^{\circ} \mathrm{C}$ for $5 \mathrm{~min}$.

After normalizing the data, the variation rates of the expression of the genes were calculated using the comparative $C_{t}\left(2^{-\Delta \Delta C T}\right)$ method and statistical analysis was then performed by independent sample T-Test utilizing SPSS version 16.0. Statistical significance was determined as $\mathrm{p}$ value $<0.05$.

Investigation of apoptosis induction in cultured cells after viral infection using flowcytometry

Induction of apoptosis in A549 cell line was detected using annexin V-fluorescein isothiocyanate (FITC)/propidium iodide (PI) apoptosis detection kit (Biolegend, San Diego, CA). According to the manufacturer's instruction, Cancer cells were plated in 6-well tissue culture plate at a concentration of 100000 cells per well in $2 \mathrm{ml}$ of culture media. Cells were infected by NDV+ integrated LV-DSCR $1^{+}$ (the best treatment for induction of apoptosis on cancer cells). After $72 \mathrm{hrs}$, apoptosis were investigated in the infected and non-infected cells were harvested and washed with cold PBS buffer, pelted and resuspended in kit binding buffer. They were treated with annexin V-FITC conjugate and incubated in dark place at RT for 15 mints. After antibody conjugation and performing PI staining $(5 \mu \mathrm{g} / \mathrm{ml})$ cells were analyzed for induction of apoptosis by flow cytometry equipment (Accuri C6 Flow Cytometer, AnnArbor, MI) within 1 hrs. The flow cytometry data obtained from a minimum of 10000 cells per sample was analysed using BD Accuri C6 Flow software.

\section{Results}

\section{Expression analysis of DSCR1 in HEK 293}

Virus particles LV DSCR1 was added medium of HEK293 culture. After 24 hours, total RNA was extracted and cDNA was synthesized. DSCR1 expression was quantified by real-time PCR in transformed and untransformed cultures compared to HPRT housekeeping gene expressions. Four times ectopic expression of DSCR1 was detected in transformed HEK293 compared to untransformed culture (Figure 1).

\section{MTT assay for NDV and LV DSCR1 ${ }^{+}$effective dose}

The effective and lethal doses for NDV and LV DSCR1 were determined on A549 and fibroblast cells using MTT assay. The optimum volume required for killing $50 \%$ of A549 cells was $0.1 \mu \mathrm{l}$ per 7000 A549 cells. The $\mathrm{IC}_{50}$ value for fibroblast cells was $0.5 \mu \mathrm{l}$ per7000 fibroblasts (Figure 2). Therapeutic index of NDV was calculated 5. For integrated LV DSCR1, ED50 and LD50 values were $6 \mu 1 / 7000$ A549 and $48 \mu \mathrm{l} / 7000$ fibroblast cells lines respectively (Figure 3 ), whereas they were $0.8 \mu \mathrm{l} / 7000 \mathrm{~A} 549$ cells and $6.4 \mu \mathrm{l} / 7000$ fibroblast cells for LV DSCR1 Non-Integrated respectively (Figure 3 ). Therapeutic index for Int. and Non Int. LV DSCR1+ was calculated as both 8 which is safer than 5 obtained for NDV.

\section{Expressions of DSCR1, in LV DSCR1 ${ }^{+}$and NDV}

DSCR1 expression is significantly increased in A549 cells transfected with integrated and non integrated LV-DSCR1 $1^{+}, 7.3$ $(\mathrm{p}=0.02)$ and 6.8 folds $(\mathrm{p}=0.04)$ compared to non-transfected cells. For NDV+ LV DSCR1 ${ }^{+}$in integrated and non integrated LV-DSCR1 $1^{+}, 9.8$ $(\mathrm{p}=0.039)$ and 12.6 folds $(\mathrm{p}=0.036)$ compared to non-transfected cells after 24 hours (Figure 4).

\section{Expression of VEGF angiogenesis marker}

Expression of VEGF is significantly decreased in A549 cells transfected with integrated and non integrated LV-DSCR $1^{+}, 5.6$ ( $\mathrm{p}=0.016)$ and 2.6 folds $(\mathrm{p}=0.021)$ compared to non-transfected cells. For NDV+ LV DSCR $1^{+}$in integrated and non integrated LV-DSCR $1^{+}$, 
Citation: Rad HM, Boroujeni ZN, Aleyasin A (2018) Ectopic Expression of DSCR1 in Conjunction with NDV Infection Reduces VEGF and Induces Apoptosis in Lung Cancer A549 Cell Line. J Cancer Sci Ther 11: 399-405. doi: 10.4172/1948-5956.1000574

$3.3(\mathrm{p}=0.04)$ and 1.5 folds ( $\mathrm{p}=0.041)$ compared to non-transfected cells after 24 hours. Expression of VEGF in NDV transfected A549 cells has increased significantly equal to 2.3 fold ( $\mathrm{p}=0.023$ ) (Figure 5).

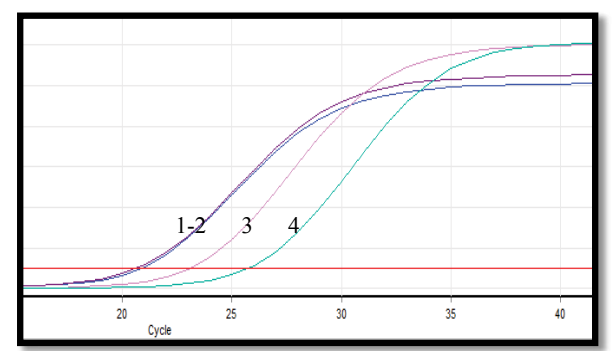

HEK

HEK+DSCR 1

Ladder

B

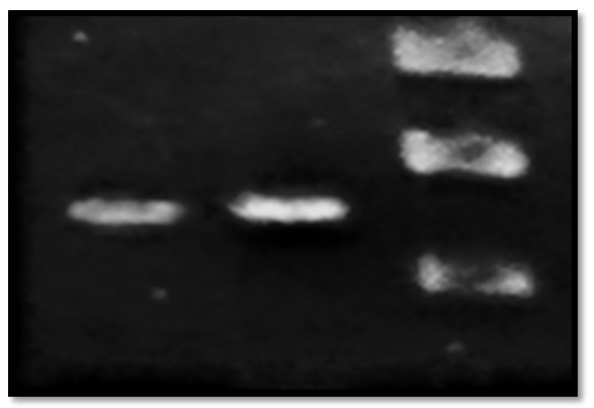

A

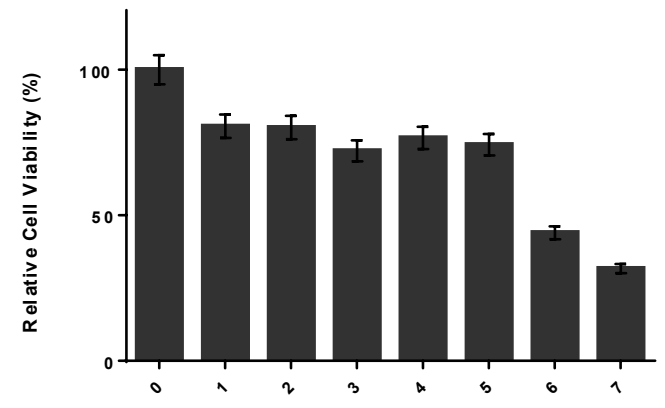

Integrate Lentiviral Vect or ( $\mu \mathrm{l} / 7000$ A549 Cells)

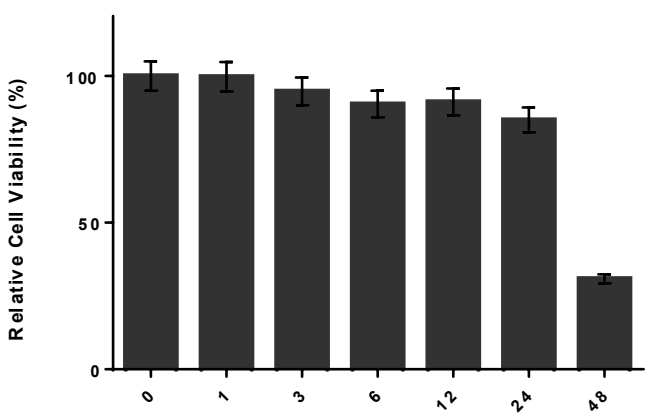

Int egra te Len tivi ral Vect or ( $\mu \mathrm{l} / 7000$ Firoblast Ce lls)

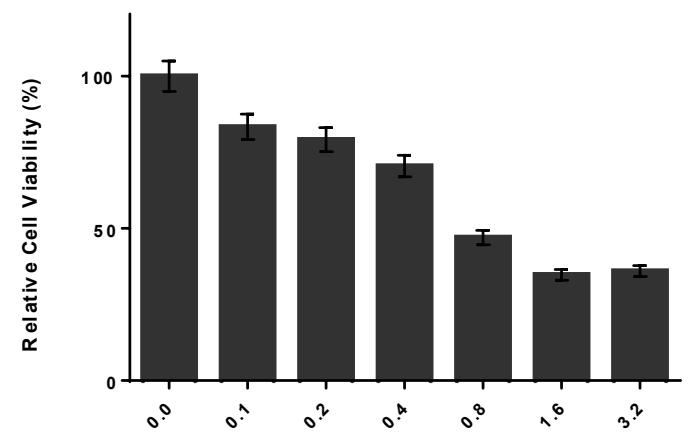

N on Integra te Len tiviral Vect or ( $\mu \mathrm{l} / 7000$ A549 Cell s)

D

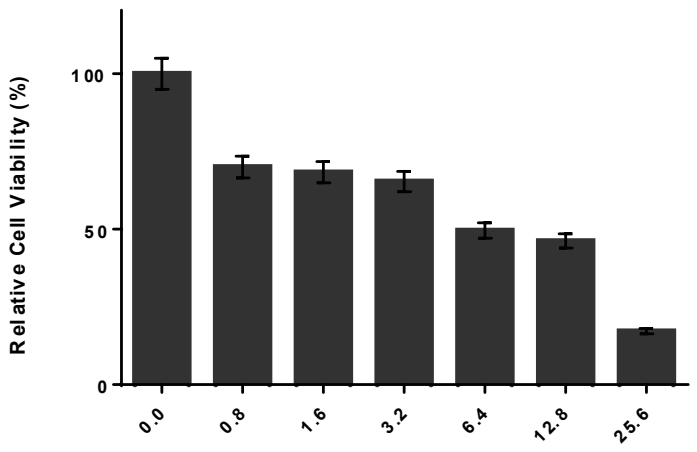

Non In tegrate Lentiviral Vector ( $\mu$ l/ 7000 Fir oblast Cel Is)

Figure 3: DSCR1 overexpression mediated by lentiviral vectors inhibited cancer cell growth. Cell viability of A549 cells (A) and fibroblasts (B) 3 days after LV Int. infection measured by MTT assay. The effects of LV Non-Int. on A549 cells (C) and fibroblasts (D).

Figure 2: Cytolytic activity of NDV on A549 lung cancer cell line (A) and fibroblast cells (B). 


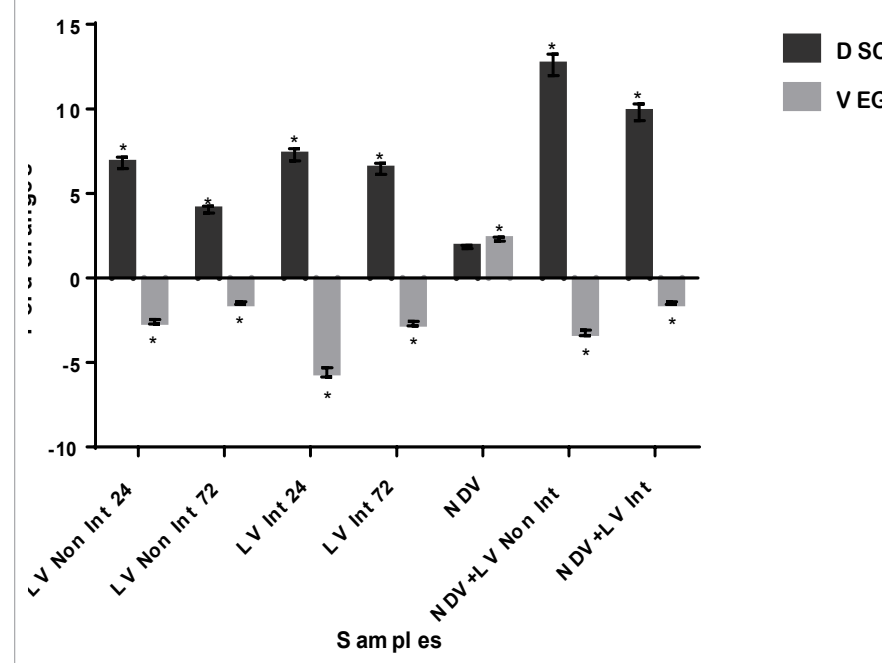

Figure 4: Changes in the expression of DSCR1 and VEGF genes within all samples. Statistical analyses were done by data normalization using HPRT housekeeping gene $(p=0.05)$.

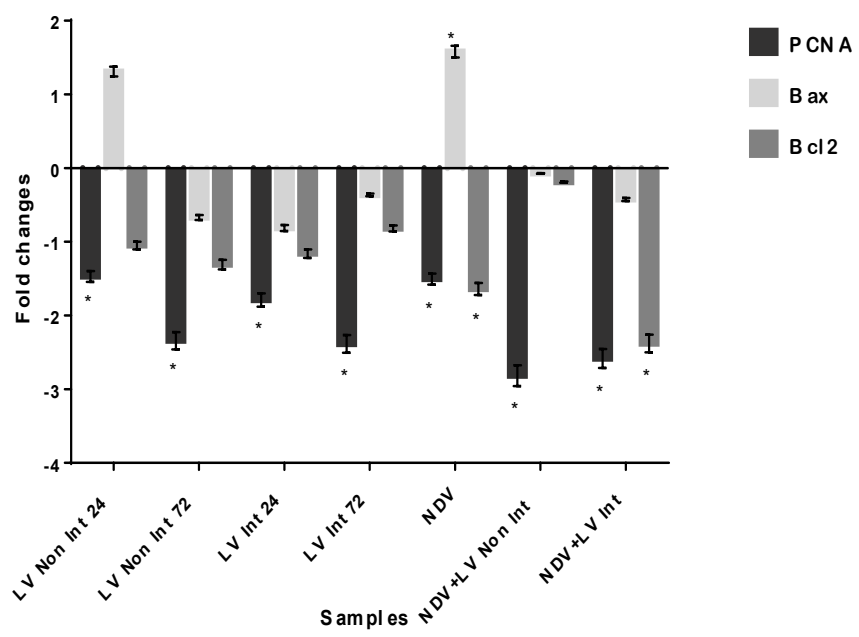

Figure 5: Expression level of PCNA, Bax and $\mathrm{Bcl}_{2}$ genes expression in all treated samples. Relative gene expressions of PCNA, Bax and $\mathrm{Bcl} 2$ were investigated in all treated samples. All PCR products were verified by electrophoresis and sequencing and relative gene expression data were analyzed using $2^{-\Delta \Delta C t}$ method. Increased and decreased expression of these genes in treated cells is meaningful $(p<0.05)$.

\begin{tabular}{|c|c|c|}
\hline Genes & Sequence (5'-3') & Size (bp) \\
\hline \multirow[t]{2}{*}{ HPRT } & CCCTGGCGTCGTGATTAGTG & \multirow{2}{*}{163} \\
\hline & GCCTCCCATCTCCTTCATCA & \\
\hline \multirow[t]{2}{*}{ DSCR1 } & AACAAGTGGAAGATGCGAC & \multirow{2}{*}{140} \\
\hline & AACAAGTGGAAGATGCGAC & \\
\hline \multirow[t]{2}{*}{ VEGF } & AACTTTCTGCTGTCTTGGGTG & \multirow{2}{*}{179} \\
\hline & AACTTTCTGCTGTCTTGGGTG & \\
\hline \multirow[t]{2}{*}{ PCNA } & AGCACCAAACCAGGAGAAAGT & \multirow{2}{*}{191} \\
\hline & TCACTCCGTCTTTTGCACAG & \\
\hline \multirow[t]{2}{*}{ Bax } & CTGACATGTTTTCTGACGGCAA & \multirow{2}{*}{140} \\
\hline & GAAGTCCAATGTCCAGCCCA & \\
\hline \multirow[t]{2}{*}{$\mathrm{BCl}_{2}$} & ATTGTGGCCTTCTTTGAGTTCG & \multirow{2}{*}{150} \\
\hline & ATCCCAGCCTCCGTTATCCT & \\
\hline
\end{tabular}

Table 1: Sequences of primers used in real-time PCR.

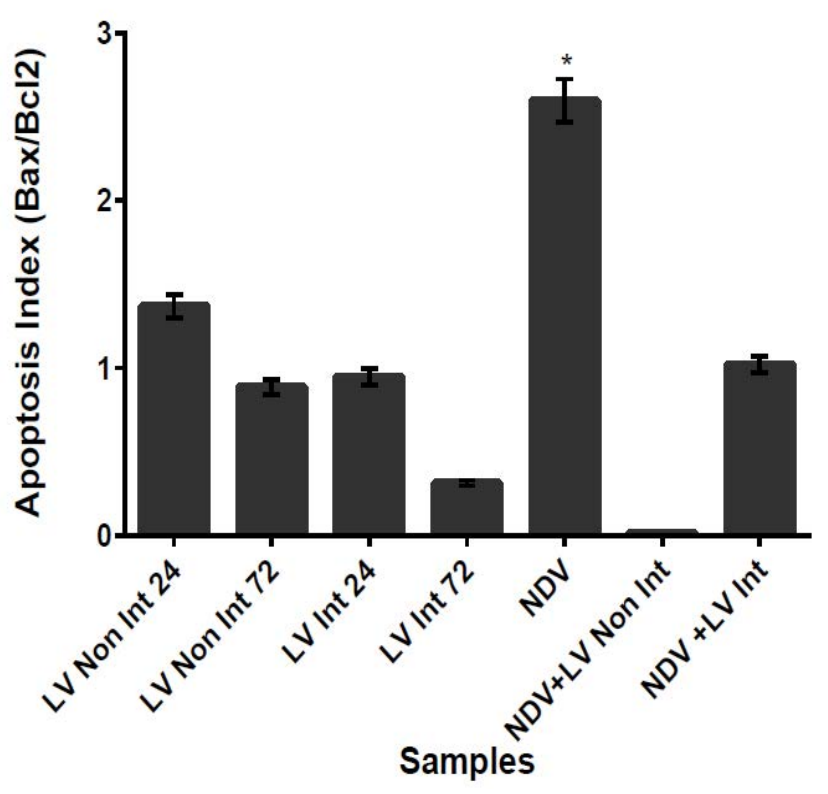

Figure 6: Apoptosis indexes for all treated samples $(p<0.05)$
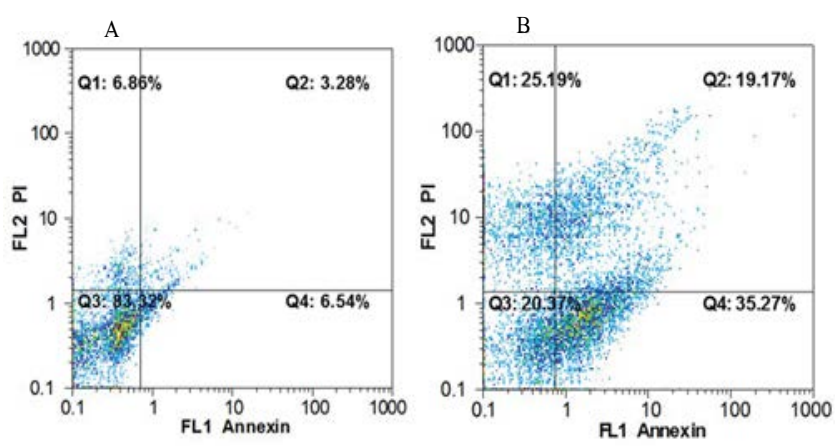

Figure 7: Investigation of apoptosis by flowcytometry assay using Annexin V-FITC/PI. NDV+ integrated LV. DSCR1+ induce apoptosis in infected cancer cells (B) in comparison to $A$ ) non-infected cancer cells.

\section{Apoptotic effects of DSCR1 gene and NDV viruses}

After 24 hours expression of PCNA gene an indirect apoptosis marker was significantly decrease 1.8 folds in LV Int. $(\mathrm{p}=0.007), 1.75$ folds in LV Non-Int. ( $\mathrm{p}=0.004), 1.5$ folds in NDV alone . $(\mathrm{p}=0.012), 2.6$ folds in NDV+LV Int. . $(\mathrm{p}=0.008)$ and 2.8 fold in NDV+LV Non Int. $(\mathrm{p}=0.001)$.

Expressions of a pro-apoptotic marker Bax and an anti-apoptotic marker $B c l 2$ involved in mitochondrial apoptosis pathway were compared after treatments to investigate the effects of DSCR1 ectopic expression and NDV infection in A549 cells. Results showed a significant 1.58 folds $(\mathrm{p}=0.04)$ increased expression of $\mathrm{Bax}$ and 1.6 folds $(\mathrm{p}=0.04)$ significant decreased the expression of $B c l 2$ gene only in NDV infected cells. Non significant expression changes were observed in other treatment conditions (Figure 6). Flowcytometry assay using Annexin V-FITC/PI has also confirmed the results of real time PCR (Figure 7).

\section{Discussion}

Cancer is a major cause of mortality in humans. In spite of current 
immense progress cancer remains a destructive disease worldwide. Considering of prevalent and high amount of lethality of this disease and also the limited efficacy and toxicities of common treatments such as chemo- and radiotherapies there will need to use effective combination therapy to suppress such a complex disease. One of this combined novel anti-cancer approaches is applying oncolytic viruses such as HSV vectors and NDV viruses in a combined cancer treatment approach as well as gene therapy for the destruction of tumor cells. In this investigation NDV were used as an oncolytic agent with apoptotic property in addition to DSCR1 gene as an anti-angiogenic factor.

Accordingly, it is important to find a cancer therapy with high efficacy selectivity killing malignant cells with fewer obstacles. Based on many studies, NDV replicates selectively in human cancerous cells while it spars normal cells and cause activate cell death program in tumor cells. The ability of NDV to replicate selectivity in cancer cells was previously known $[10,16,21,44]$. NDV could induce apoptosis in cancer cells by both intracellular and extracellular pathways $[16,21,45]$. One limitation for using NDV virus as oncolytic agent is related to its angiogenesis properties in tumor tissues [23]. Subsequently several different NDV strains including 73-T, Ulster, MTH-68, Italien, Hickman, PV701, HUJ and LaSota were used against a variety of human neoplasms [46]. The first report of the application of NDV to treat human cancers was in the early 1950s, in that research adenovirus and NDV were injected directly into uterine carcinoma and partial necrosis and sloughing was observed, but in follow regrowth was happened [47]. Othman et al. showed that NDV strain AF2240 has the ability to infect MCF7 cell line resulting in apoptosis [48]. NDV-LaSota strain was shown to be more susceptible to apoptosis resistant cells [49]. Another study was showed that MCF7-CR cells are susceptible to NDV infection which highlight the importance of surviving in the oncolytic effects of NDV in chemo resistant cancer cells [50]. Mansour et al. demonstrated that NDV-HUJinduced oncolysis in chemoresistant malignant melanoma specimens [49]. Several solid tumors including prostate, epidermoid, colon, large cell lung, breast and low passage colon carcinoma xenografts treated with the strain 73-T regressed effectively [51]. Other study suggested that use of NDV strains AF2240 and V4-UPM as an oncolytic agent of WEHI-3B myelomoncytic leukemia cells and its cytotoxicity increased with increasing titers of the virus [52]. NDV AF2240 strain induced apoptosis in MCF-7 cells was most probably mediated by HN protein expression alone [53].

In this study to improve the oncolytic effect of NDV virus, its angiogenesis and apoptotic effects were studied in conjunction with ectopic expression of DSCR1 gene by lentiviral vector in lung cancer cells A549. DSCR1 play its anti-angiogenesis role due to interruption in angiogenesis signaling pathways by down regulating VEGF gene expression [31,54]. Our result has indicated for the first time significant increase in VEGF gene expression $(p=0.023)$ up to 2.3 fold in A549 cancer cells after NDV infection alone. However, simultaneously infections with NDV and integrated and Nonintegrated LV-DSCR1+ reduce VEGF expressions significantly by $1.5(\mathrm{p}=0.04)$ and 3.25 $(\mathrm{p}=0.04)$ times respectively in comparison to non-treated A549 cancer cells. Increasing level of DSCR1 gene expression could block the VEGF-Calcineurin-NFAT pathway in endothelial cells in vitro [55]. Shine et al. observed that a single extra copy of DSCR1 gene could suppress lung tumor angiogenesis in mouse model developing human adenocarcinoma [56]. Our data on integrated and non-integrated LV-DSCR $1+$ indicated its 7 folds after 24 his however after $72 \mathrm{hrs}$ its expression remained 6.4 in integrated and decreases to 4 folds in nonintegrated. It means a significant decrease in the expression of DSCR 1 in on integrated LV after $72 \mathrm{hrs.} \mathrm{DSCR1} \mathrm{expression} \mathrm{simultaneous}$ infection of NDV + LV-DSCR1 increased significantly to a higher level 10 and 12 fold for integrated and non-integrated LV respectively.

PCNA decreased 1.5 fold $(\mathrm{p}=0.0126)$ and Bax pro apoptotic gene increased 1.6 fold $(\mathrm{p}=0.04)$ and $B c l 2$ anti-apoptotic gene decreased 1.6 fold $(\mathrm{p}=0.04)$ significantly. Moreover, apoptosis index for NDV sample was about 2.6 and significant. This result showed that NDV used mitochondrial pathway for induction of cell death (Figure 6).

When DSCR1 increase in neural and primary cells, total ROS accumulate and similarly decrease cell viability in response to high level of $\mathrm{H}_{2} \mathrm{O}_{2}$ [30]. This is the first study to investigate apoptotic effect of DSCR1 ectopic over expression on lung cancer cells. Over expression of DSCR1 has been suggested to induce apoptotic activation through caspase 9 and 3 pathway in neurons [57]. Activation of caspase 3 reduces PCNA gene expression an indirect apoptosis marker to induce cell death. After DSCR1 ectopic expression, PCNA was decreased significantly but variations in Bax and $B c l 2$, two mitochondrial apoptosis markers, were not to be significant. This means that DSCR1 does not use apoptotic intracellular pathway (Figure 6).

Baek et al. showed that a transgenic copy of DSCR1 is sufficient to confer significant suppression of tumor growth in mice by dampening VEGF- calcineurin signaling [58]. VEGF-mediated angiogenesis is central to tumor progression and has become a therapeutic target for anticancer treatment. Minami et al. demonstrated that overexpression of DSCR 1 inhibited lung metastases in mouse models. DSCR 1 is directly blocking calcineurin phosphatase function and deletion of Dscr 1 in a transgenic mouse model leads to hyperactivation of calcineurin-NFAT signaling. In this study for the first time DSCR1 gene was transferred to lung cancer cells using non-integrated lentiviral vectors. After cell infection the increasing in the DSCR1 expression and the VEGF reduction were observed by real time RT-PCR. Decreasing of VEGF expression caused to the reduction in angiogenesis that is effective in tumor growth inhibition and cancer treatment. Lentiviral vectors can deliver transgenes to a wide variety of dividing and nondividing cells and maintain stable long-term transgene expression. This is the first study to investigate the application of non-integrated lentiviruses harboring DSCR1 in inhibition of angiogenesis in lung cancer cells in the culture.

$\mathrm{Su}$ et al. shown that Anti-angiogenesis gene therapy combining with viral oncolytic therapy provides new slights for human cancer therapy. Antiangiogenesis effect due to gene expression and the selective viral replication and oncolysis of cancer cells, suggesting that the combination of gene therapy and virotherapy can provide a new therapeutic strategy to increase the probable of cancer treatment. In this approach for the first time we investigated the apoptotic effects on NDV virus in combination with the anti angiogenic effect of DSCR1 gene via lenitviruse in lung cancer cells. In current study LV-DSCR $1^{+}$ and NDV-Lasota were used simultaneously to infection of A549 cancer cells for intensify their anti-cancer properties. Based on our results, PCNA decreased 1.5 fold $(\mathrm{p}=0.0126)$ and Bax pro apoptotic gene increased 1.6 fold $(\mathrm{p}=0.04)$ and $B c l 2$ anti-apoptotic gene decreased 1.6 fold ( $\mathrm{p}=0.04$ ) significantly. Moreover, apoptosis index for NDV sample was about 2.6 and significant. This result showed that NDV used mitochondrial pathway for induction of cell death.

\section{Conclusion}

Based on these results, we can conclude that the higher levels of apoptosis occurred in cancer cells in co-infection by NDV and lentiviruses. The higher levels of apoptosis in cancer cells have occurred is result of high proliferation and cytotoxicity in cancer cells compared 
Citation: Rad HM, Boroujeni ZN, Aleyasin A (2018) Ectopic Expression of DSCR1 in Conjunction with NDV Infection Reduces VEGF and Induces Apoptosis in Lung Cancer A549 Cell Line. J Cancer Sci Ther 11: 399-405. doi: 10.4172/1948-5956.1000574

to normal cells infected by NDV resulting in elevated levels of apoptosis in both virus inoculum to inoculate NDV virus alone caused more damage to cell membranes caused by the simultaneous arrival of two NDV virus and lentiviral the simultaneous inoculation. In summary, results demonstrated that combination of NDV virus with LV-DSCR $1^{+}$ can be efficient for lung cancer treatment.

\section{References}

1. Hanahan D, Weinberg RA (2011) Hallmarks of cancer: The next generation. Cell 144: 646-674.

2. Ravindra PV, Tiwari AK, Sharma B, Chauhan RS (2009) Newcastle disease virus as an oncolytic agent. Indian J Med Res 130: 507-513.

3. Siegel R, Naishadham D, Jemal A (2013) Cancer statistics, 2013. CA Cancer J Clin 63: 11-30.

4. National Cancer Institute: (2010) Cancer Stat Facts: Lung and Bronchus Cancer Surveillance, epidemiology and end results program.

5. Tsvetkova E, Goss GD (2012) Drug resistance and its significance for treatment decisions in non-small-cell lung cancer. Curr Oncol 19: S45-51.

6. Neal RD, Hamilton W, Rogers TK (2014) Lung cancer. BMJ 349: g6560.

7. Yaacov B, Eliahoo E, Lazar I, Ben-Shlomo M, Greenbaum I, et al. (2008) Selective oncolytic effect of an attenuated Newcastle disease virus (NDV-HUJ) in lung tumors. Cancer Gene Ther 15: 795-807.

8. Heffner JE (2009) Fishman's pulmonary diseases and disorders. Res Care 54 268-269.

9. Reveiz L, Rueda JR, Cardona AF (2008) Palliative endobronchial brachytherapy for non-small cell lung cancer. Cochrane Database Syst Rev 12: CD004284.

10. Beljanski V, Hiscott $J$ (2012) The use of oncolytic viruses to overcome lung cancer drug resistance. Curr Opin Virol 2: 629-635.

11. Alabsi AM, Bakar SA, Ali R, Omar AR, Bejo MH, et al. (2011) Effects of newcastle disease virus strains AF2240 and V4-UPM on cytolysis and apoptosis of leukemia cell lines. Int J Mol Sci 12: 8645-8660.

12. Ali R, Alabsi AM, Ali AM, Ideris A, Omar AR, et al. (2011) Cytolytic effects and apoptosis induction of newcastle disease virus strain AF2240 on anaplastic astrocytoma brain tumor cell line. Neurochem Res 36: 2051-2062.

13. Singh PK, Doley J, Kumar R, Sahoo AP, Tiwari AK (2012) Oncolytic viruses \& their specific targeting to tumour cells. Indian J Med Res 136: 571-584.

14. Nguyen TL, Wilson MG, Hiscott J (2010) Oncolytic viruses and histone deacetylase inhibitors-a multi-pronged strategy to target tumor cells. Cytokine Growth Factor Rev 21: 153-159.

15. Liu K, Ma Y, Wang J, Mu H, Gao C, et al. (2013) Complete genome sequencing and analysis of an anti-tumor Newcastle disease virus strain. Gene 525: 47-57.

16. Meerani S, Yao Y (2010) Oncolytic viruses in cancer therapy. Eur J Sci Res 40: $156-171$

17. Fu F, Zhao M, Yang YJ, Tong GZ, Yang BF, et al. (2011) Antiproliferative effect of newcastle disease virus strain D90 on human lung cancer cell line A549. Oncol Res 19: 323-333.

18. Elankumaran S, Rockemann D, Samal SK (2006) Newcastle disease virus exerts oncolysis by both intrinsic and extrinsic caspase-dependent pathways of cell death. J Virol 80: 7522-7534.

19. Fournier $P$, Schirrmacher $V$ (2013) Oncolytic newcastle disease virus as cutting edge between tumor and host. Biology 2: 936-975

20. Lam HY, Yeap SK, Pirozyan MR, Omar AR, Yusoff K, et al. (2011) Safety and clinical usage of newcastle disease virus in cancer therapy. $\mathrm{J}$ Biomed Biotechnol 2011: 718710 .

21. Mansour M, Palese P, Zamarin D (2011) Oncolytic specificity of newcastle disease virus is mediated by selectivity for apoptosis-resistant cells. J Virol 85 6015-6023.

22. Fábián Z, Csatary CM, Szeberényi J, Csatary LK (2007) p53-independent endoplasmic reticulum stress-mediated cytotoxicity of a Newcastle disease virus strain in tumor cell lines. J Virol 81: 2817-2830.

23. Wojton J, Kaur B (2010) Impact of tumor microenvironment on oncolytic viral therapy. Cytokine Growth Factor Rev 21: 127-134
24. Frantz S, Vincent KA, Feron O, Kelly RA (2005) Innate immunity and angiogenesis. Circ Res 96: 15-26.

25. Zhang W, Fulci G, Wakimoto H, Cheema TA, Buhrman JS, et al. (2013) Combination of oncolytic herpes simplex viruses armed with angiostatin and IL-12 enhances antitumor efficacy in human glioblastoma models. Neoplasia 15: $591-599$.

26. Tysome JR, Lemoine NR, Wang Y (2013) Update on oncolytic viral therapytargeting angiogenesis. Onco Targets Ther 6: 1031-1040.

27. Hutzen B, Bid HK, Houghton PJ, Pierson CR, Powell K, et al. (2014) Treatment of medulloblastoma with oncolytic measles viruses expressing the angiogenesis inhibitors endostatin and angiostatin. BMC cancer 14: 206.

28. Gholami S, Marano A, Chen NG, Aguilar RJ, Frentzen A, et al. (2014) A nove vaccinia virus with dual oncolytic and anti-angiogenic therapeutic effects against triple-negative breast cancer. Breast Cancer Res Treat 148: 489-499.

29. Brait VH, Martin KR, Corlett A, Broughton BR, Kim HA, et al. (2012) Overexpression of DSCR1 protects against post-ischemic neuronal injury. PloS one 7: e47841.

30. Peiris H, Dubach D, Jessup CF, Unterweger $P$, Raghupathi $R$, et al. (2014) RCAN1 regulates mitochondrial function and increases susceptibility to oxidative stress in mammalian cells. Oxid Med Cell Longev 2014:520316.

31. Pritchard MA, Martin KR (2013) RCAN1 and its potential contribution to the down syndrome phenotype. Down syndrome, Subrata kumar Dey, Intech open.

32. Catlett TS, Gomez TM (2016) Division of labor in the growth cone by DSCR1. J. Cell Biol 213: 407-409.

33. Genescà L, Aubareda A, Fuentes JJ, Estivill X, De La Luna S, et al. (2003) Phosphorylation of calcipressin 1 increases its ability to inhibit calcineurin and decreases calcipressin half-life. Biochem J 374: 567-575.

34. Ermak G, Hench KJ, Chang KT, Sachdev S, Davies KJ (2009) Regulator of calcineurin (RCAN1-1L) is deficient in Huntington disease and protective against mutant huntingtin toxicity in vitro. J Biol Chem 284: 11845-11853.

35. Fuentes JJ, Genescà L, Kingsbury TJ, Cunningham KW, Pérez-Riba M, et al (2000) DSCR1, overexpressed in Down syndrome, is an inhibitor of calcineurinmediated signaling pathways. Hum Mol Genet 9: 1681-1690.

36. Berridge MJ (2014) Sensors and effectors. Cell Sig Biol 4: 1-96.

37. Lee MY, Garvey SM, Baras AS, Lemmon JA, Gomez MF, et al. (2010) Integrative genomics identifies DSCR1 (RCAN1) as a novel NFAT-dependent mediator of phenotypic modulation in vascular smooth muscle cells. Hum Mol Genet 19: 468-479.

38. Qin L, Zhao D, Liu X, Nagy JA, Hoang MV, et al. (2006) Down syndrome candidate region 1 isoform 1 mediates angiogenesis through the calcineurinNFAT pathway. Mol Cancer Res 4: 811-820.

39. Annoni A, Goudy K, Akbarpour M, Naldini L, Roncarolo MG (2013) Immune responses in liver-directed lentiviral gene therapy. TransI Res 161: 230-240.

40. Cockrell AS, Kafri T (2007) Gene delivery by lentivirus vectors. Mol Biotechno 36: 184-204.

41. Kafri T, Van Praag H, Gage FH, Verma IM (2000) Lentiviral vectors: regulated gene expression. Mol Ther 1: 516-521.

42. Mátrai J, Chuah MK, Vanden Driessche T (2010) Recent advances in lentivira vector development and applications. Mol Ther 18: 477-490.

43. McGinnes LW, Pantua H, Reitter J, Morrison TG (2006) Newcastle disease virus: propagation, quantification, and storage. Curr Protoc Microbiol 15: Unit $15 \mathrm{~F} .2$

44. Zamarin D, Palese P (2012) Oncolytic newcastle disease virus for cance therapy: Old challenges and new directions. Future Microbiol 7: 347-367.

45. Cassel WA, Garrett RE (1965) Newcastle disease virus as an antineoplastic agent. Cancer 18: 863-868

46. Othman F, Ideris A, Motalleb G, Eshak ZB, Rahmat A (2010) Oncolytic effect of Newcastle disease virus AF2240 strain on the MCF-7 breast cancer cell line. Yakhteh 12: 17-24.

47. Jamal MH, Ch'ng WC, Yusoff K, Shafee N (2012) Reduced newcastle disease virus-induced oncolysis in a subpopulation of cisplatin-resistant MCF7 cells is associated with survivin stabilization. Cancer Cell Int 12: 35. 
Citation: Rad HM, Boroujeni ZN, Aleyasin A (2018) Ectopic Expression of DSCR1 in Conjunction with NDV Infection Reduces VEGF and Induces Apoptosis in Lung Cancer A549 Cell Line. J Cancer Sci Ther 11: 399-405. doi: 10.4172/1948-5956.1000574

48. Phuangsab A, Lorence RM, Reichard KW, Peeples ME, Walter RJ (2001) Newcastle disease virus therapy of human tumor xenografts: antitumor effects of local or systemic administration. Cancer Lett 172: 27-36.

49. Ghrici M, El Zowalaty M, Omar AR, Ideris A (2013) Induction of apoptosis in MCF-7 cells by the hemagglutinin-neuraminidase glycoprotein of Newcastle disease virus Malaysian strain AF2240. Oncol Rep 30: 1035-1044.

50. Puhlmann J, Puehler F, Mumberg D, Boukamp P, Beier R (2010) Rac1 is required for oncolytic NDV replication in human cancer cells and establishes a link between tumorigenesis and sensitivity to oncolytic virus. Oncogene 29: 2205-2216.

51. Bian J, Wang K, Kong X, Liu H, Chen F, et al. (2011) Caspase-and p38-MAPKdependent induction of apoptosis in A549 lung cancer cells by Newcastle disease virus. Arch Virol 156: 1335-1344.

52. Holmes K, Chapman E, See V, Cross MJ (2010) VEGF Stimulates RCAN1.4 expression in endothelial cells via a pathway requiring $\mathrm{Ca}^{2+} /$ calcineurin and protein kinase $\mathrm{C}-\delta$. PloS one 5: e11435.

53. Hesser BA, Liang XH, Camenisch G, Yang S, Lewin DA, et al. (2004) Down syndrome critical region protein 1 (DSCR1), a novel VEGF target gene that regulates expression of inflammatory markers on activated endothelial cells. Blood 104: 149-158.

54. Baek KH, Zaslavsky A, Lynch RC, Britt C, Okada Y, et al. (2009) Down's syndrome suppression of tumour growth and the role of the calcineurin inhibitor DSCR1. Nature 459: 1126-1130.

55. Sunshine SB, Dallabrida SM, Durand E, Ismail NS, Bazinet L, et al. (2012) Endostatin lowers blood pressure via nitric oxide and prevents hypertension associated with VEGF inhibition. Proc Natl Acad Sci USA 109: 11306-11311.

56. Ryeom S, Greenwald RJ, Sharpe AH, McKeon F (2003) The threshold pattern of calcineurin-dependent gene expression is altered by loss of the endogenous inhibitor calcipressin. Nat Immunol 4: 874-881.

57. An DS, Wersto RP, Metzger ME, Lu S, Amado RG, et al. (2000) Marking and gene expression by a lentivirus vector in transplanted human and nonhuman primate CD34+ cells. J Virol 74: 1286-1295.

58. Su C, Na M, Chen J, Wang X, Liu Y, et al. (2008) Gene-viral cancer therapy using dual-regulated oncolytic adenovirus with antiangiogenesis gene for increased efficacy. Mol Cancer Res 6: 568-575. 